\title{
Daniel BARIL
}

Anthropologue et journaliste

(2012)

\section{"L’idée d’une charte de la laïcité ne déplairait pas à Claude Lévi-Strauss.”}

Devant la dérive du multiculturalisme, le célèbre penseur de l'anthropologie ethnologue refuserait la laïcité ouverte et le cours ECR

Un document produit en version numérique par Jean-Marie Tremblay, bénévole, professeur de sociologie au Cégep de Chicoutimi

Courriel: jean-marie tremblay@uqac.ca

Site web pédagogique : http://www.uqac.ca/jmt-sociologue/

Dans le cadre de: "Les classiques des sciences sociales" Une bibliothèque numérique fondée et dirigée par Jean-Marie Tremblay, professeur de sociologie au Cégep de Chicoutimi

Site web: http://classiques.uqac.ca/

Une collection développée en collaboration avec la Bibliothèque Paul-Émile-Boulet de l'Université du Québec à Chicoutimi Site web: http://bibliotheque.uqac.ca/ 


\section{Politique d'utilisation de la bibliothèque des Classiques}

Toute reproduction et rediffusion de nos fichiers est interdite, même avec la mention de leur provenance, sans l'autorisation formelle, écrite, du fondateur des Classiques des sciences sociales, Jean-Marie Tremblay, sociologue.

Les fichiers des Classiques des sciences sociales ne peuvent sans autorisation formelle:

- être hébergés (en fichier ou page web, en totalité ou en partie) sur un serveur autre que celui des Classiques.

- servir de base de travail à un autre fichier modifié ensuite par tout autre moyen (couleur, police, mise en page, extraits, support, etc...),

Les fichiers (.html, .doc, .pdf., .rtf, .jpg, .gif) disponibles sur le site Les Classiques des sciences sociales sont la propriété des Classiques des sciences sociales, un organisme à but non lucratif composé exclusivement de bénévoles.

Ils sont disponibles pour une utilisation intellectuelle et personnelle et, en aucun cas, commerciale. Toute utilisation à des fins commerciales des fichiers sur ce site est strictement interdite et toute rediffusion est également strictement interdite.

L'accès à notre travail est libre et gratuit à tous les utilisateurs. C'est notre mission.

Jean-Marie Tremblay, sociologue

Fondateur et Président-directeur général,

LES CLASSIQUES DES SCIENCES SOCIALES. 
Cette édition électronique a été réalisée par Jean-Marie Tremblay, bénévole, professeur de sociologie au Cégep de Chicoutimi à partir de :

\section{Daniel BARIL}

“L’idée d’une charte de la laïcité ne déplairait pas à Claude Lévi-Strauss. Devant la dérive du multiculturalisme, le célèbre penseur de l'anthropologie ethnologue refuserait la laïcité ouverte et le cours ECR.”

Un article publié dans LE DEVOIR, Montréal, édition du samedi 29 septembre 2012, page B6 - le devoir de philo.

[Autorisation formelle accordée par l'auteur le 2 octobre 2012 de diffuser cet article dans Les Classiques des sciences sociales.]

Courriel : daniel.baril@umontreal.ca

Polices de caractères utilisée :

Pour le texte: Times New Roman, 14 points.

Pour les notes de bas de page : Times New Roman, 12 points.

Édition électronique réalisée avec le traitement de textes Microsoft Word 2008 pour Macintosh.

Mise en page sur papier format : LETTRE US, 8.5'” x 11'’.

Édition numérique réalisée le 2 octobre 2012 à Chicoutimi, Ville de Saguenay, Québec. 


\section{Daniel Baril}

Professeur de Science politique à l'Université du Québec à Montréal

Doyen de la Faculté de Science Politique et de Droit, Université du Québec a Montréal

\section{L’idée d'une charte de la laïcité ne déplairait pas à Claude Lévi-Strauss}

Devant la dérive du multiculturalisme, le célèbre penseur de l'anthropologie ethnologue refuserait la laïcité ouverte et le cours ECR.”

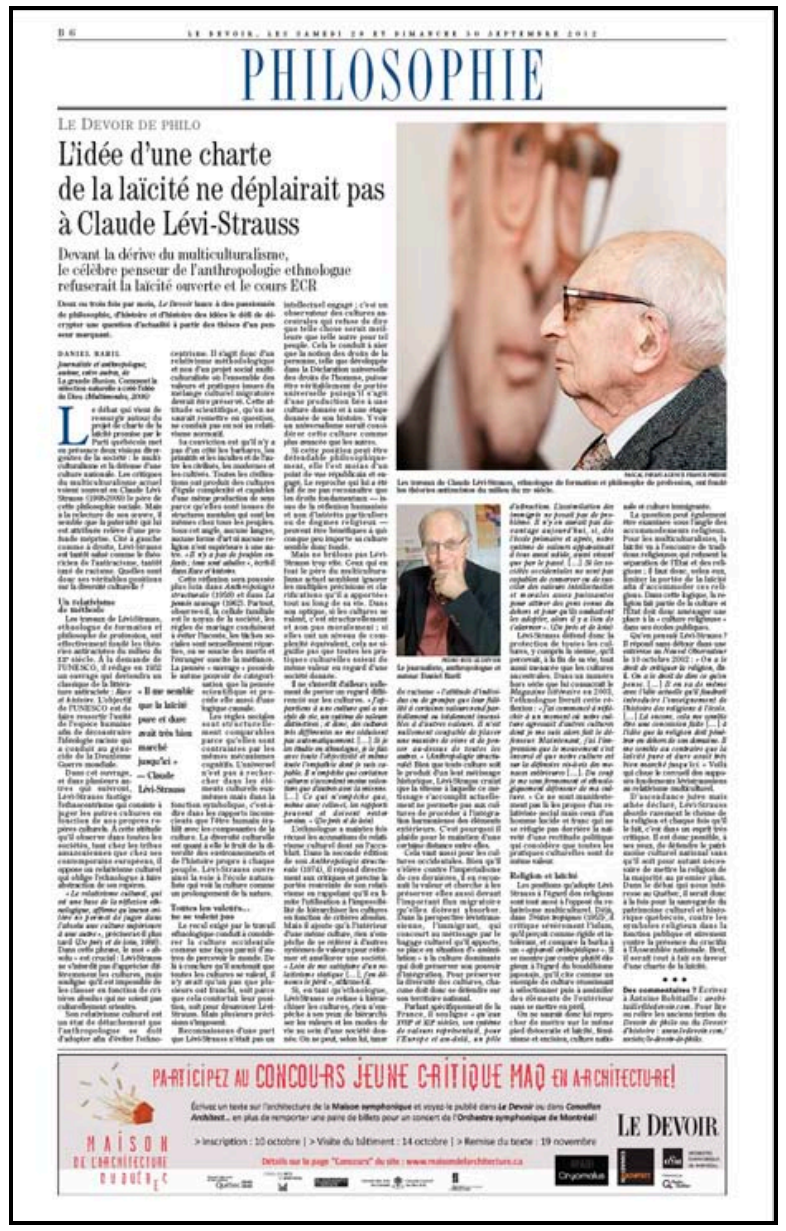

Un article publié dans LE DEVOIR, Montréal, édition du samedi 29 septembre 2012, page B6 - le devoir de philo. 


\section{Daniel Baril}

Journaliste et anthropologue

L’idée d'une charte de la laïcité

ne déplairait pas à Claude Lévi-Strauss

Devant la dérive du multiculturalisme, le célèbre penseur

de l'anthropologie ethnologue refuserait la laïcité ouverte et le cours ECR.”

Un article publié dans LE DEVOIR, Montréal, édition du samedi 29 septembre 2012, page B6 - le devoir de philo.

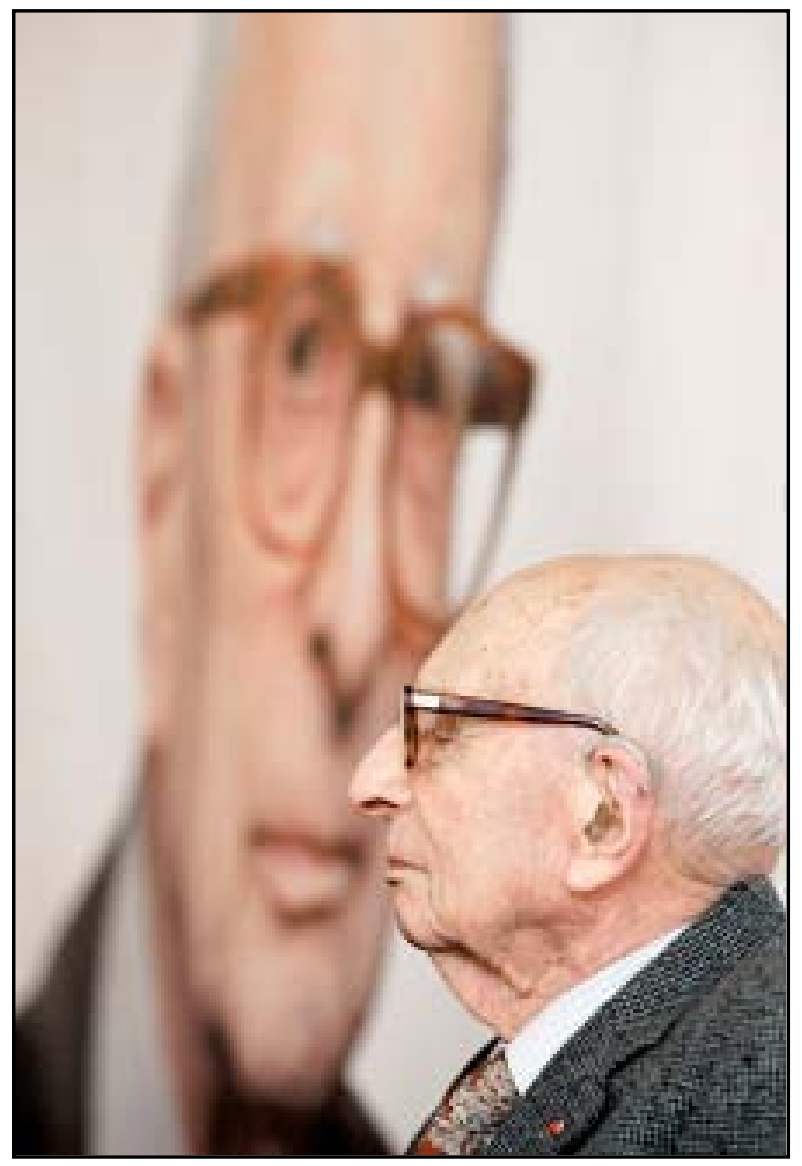

Daniel Baril

Journaliste et anthropologue, auteur, entre autres, de La grande illusion. Comment la sélection naturelle a créé l'idée de Dieu (Multimondes, 2006)

Photo: Agence France-Presse Pascal Pavani. Les travaux de Claude LéviStrauss, ethnologue de formation et philosophe de profession, ont fondé les théories antiracistes du milieu du XXe siècle.

Deux ou trois fois par mois, Le Devoir lance à des passionnés de philosophie, d'histoire et d'histoire des idées le défi de décrypter une question d'actualité à partir des thèses d'un penseur marquant.

Le débat qui vient de ressurgir autour du projet de charte de la laïcité promise par le Parti québécois met en présence deux visions divergentes de la société : le multiculturalisme et la défense d'une culture nationale. Les critiques du multiculturalisme actuel voient souvent en Claude Lévi-Strauss (1908-2009) le père de cette philosophie 
sociale. Mais à la relecture de son oeuvre, il semble que la paternité qui lui est attribuée relève d'une profonde méprise. Cité à gauche comme à droite, Lévi-Strauss est tantôt salué comme le théoricien de l'antiracisme, tantôt taxé de racisme. Quelles sont donc ses véritables positions sur la diversité culturelle?

\section{Un relativisme de méthode}

Les travaux de Lévi-Strauss, ethnologue de formation et philosophe de profession, ont effectivement fondé les théories antiracistes du milieu du XXe siècle. À la demande de l'UNESCO, il rédige en 1952 un ouvrage qui deviendra un classique de la littérature antiraciste : Race et histoire. L'objectif de l'UNESCO est de faire ressortir l'unité de l'espèce humaine afin de déconstruire l'idéologie raciste qui a conduit au génocide de la Deuxième Guerre mondiale.

Dans cet ouvrage, et dans plusieurs autres qui suivront, LéviStrauss fustige l'ethnocentrisme qui consiste à juger les autres cultures en fonction de nos propres repères culturels. À cette attitude qu'il observe dans toutes les sociétés, tant chez les tribus amazoniennes que chez ses contemporains européens, il oppose un relativisme culturel qui oblige l'ethnologue à faire abstraction de ses repères.

«Le relativisme culturel, qui est une base de la réflexion ethnologique, affirme qu'aucun critère ne permet de juger dans l'absolu une culture supérieure à une autre ", précisera-t-il plus tard (De près et de loin, 1988). Dans cette phrase, le mot «absolu » est crucial : LéviStrauss ne s'interdit pas d'apprécier différemment les cultures, mais souligne qu'il est impossible de les classer en fonction de critères absolus qui ne soient pas culturellement orientés.

Son relativisme culturel est un état de détachement que l'anthropologue se doit d'adopter afin d'éviter l'ethnocentrisme. Il s'agit donc d'un relativisme méthodologique et non d'un projet social multiculturaliste où l'ensemble des valeurs et pratiques issues du mélange culturel migratoire devrait être préservé. Cette attitude scientifique, qu'on ne saurait remettre en question, ne conduit pas en soi au relativisme normatif. 
Sa conviction est qu'il n’y a pas d'un côté les barbares, les primitifs et les incultes et de l'autre les civilisés, les modernes et les cultivés. Toutes les civilisations ont produit des cultures d'égale complexité et capables d'une même production de sens parce qu'elles sont issues de structures mentales qui sont les mêmes chez tous les peuples. Sous cet angle, aucune langue, aucune forme d'art ni aucune religion n'est supérieure à une autre. "Il n'y a pas de peuples enfants ; tous sont adultes », écrit-il dans Race et histoire.

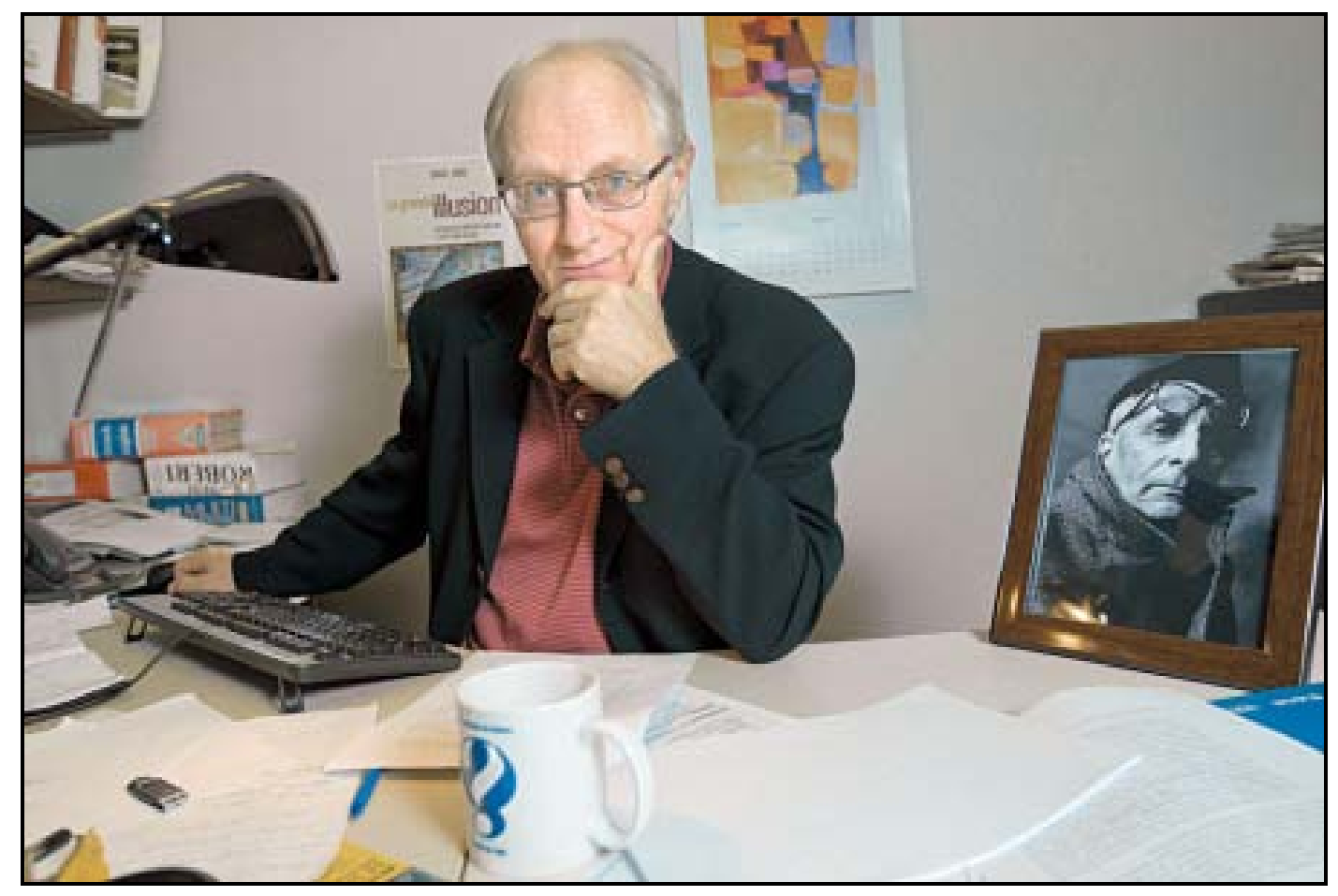

Le journaliste, anthropologue et auteur Daniel Baril

Cette réflexion sera poussée plus loin dans Anthropologie structurale (1958) et dans La pensée sauvage (1962). Partout, observe-t-il, la cellule familiale est le noyau de la société, les règles de mariage conduisent à éviter l'inceste, les tâches sociales sont sexuellement réparties, on se soucie des morts et l'étranger suscite la méfiance. La pensée "sauvage " possède le même pouvoir de catégorisation que la pensée scientifique et procède elle aussi d'une logique causale.

Les règles sociales sont structurellement comparables parce qu'elles sont contraintes par les mêmes mécanismes cognitifs. 
L'universel n'est pas à rechercher dans les éléments culturels euxmêmes mais dans la fonction symbolique, c'est-à-dire dans les rapports inconscients que l'être humain établit avec les composantes de la culture. La diversité culturelle est quant à elle le fruit de la diversité des environnements et de l'histoire propre à chaque peuple. LéviStrauss ouvre ainsi la voie à l'école naturaliste qui voit la culture comme un prolongement de la nature.

\section{Toutes les valeurs... ne se valent pas}

Le recul exigé par le travail ethnologique conduit à considérer la culture occidentale comme une façon parmi d'autres de percevoir le monde. De là à conclure qu'il soutenait que toutes les cultures se valent, il n'y avait qu'un pas que plusieurs ont franchi, soit parce que cela confortait leur position, soit pour désavouer Lévi-Strauss. Mais plusieurs précisions s’imposent.

Reconnaissons d'une part que Lévi-Strauss n'était pas un intellectuel engagé ; c'est un observateur des cultures ancestrales qui refuse de dire que telle chose serait meilleure que telle autre pour tel peuple. Cela le conduit à nier que la notion des droits de la personne, telle que développée dans la Déclaration universelle des droits de l'homme, puisse être véritablement de portée universelle puisqu'il s'agit d'une production liée à une culture donnée et à une étape donnée de son histoire. Y voir un universalisme serait considérer cette culture comme plus avancée que les autres.

Si cette position peut être défendable philosophiquement, elle l'est moins d'un point de vue républicain et engagé. Le reproche qui lui a été fait de ne pas reconnaître que les droits fondamentaux - issus de la réflexion humaniste et non d'intérêts particuliers ou de dogmes religieux - peuvent être bénéfiques à quiconque peu importe sa culture semble donc fondé.

Mais ne brûlons pas Lévi-Strauss trop vite. Ceux qui en font le père du multiculturalisme actuel semblent ignorer les multiples précisions et clarifications qu'il a apportées tout au long de sa vie. Dans son optique, si les cultures se valent, c'est structurellement et non pas moralement ; si elles ont un niveau de complexité équivalent, cela ne 
signifie pas que toutes les pratiques culturelles soient de même valeur en regard d'une société donnée.

Il ne s'interdit d'ailleurs nullement de porter un regard différencié sur les cultures. "J'appartiens à une culture qui a un style de vie, un système de valeurs distinctives; et donc, des cultures très différentes ne me séduisent pas automatiquement. [...] Si je les étudie en ethnologue, je le fais avec toute l'objectivité et même toute l'empathie dont je suis capable. Il n'empêche que certaines cultures s'accordent moins volontiers que d'autres avec la mienne. [...] Ce qui n'empêche que, même avec celles-ci, les rapports peuvent et doivent rester sereins. " (De près et de loin)

L'ethnologue a maintes fois récusé les accusations de relativisme culturel dont on l'accablait. Dans la seconde édition de son Anthropologie structurale (1974), il répond directement aux critiques et précise la portée restreinte de son relativisme en rappelant qu'il en limite l'utilisation à l'impossibilité de hiérarchiser les cultures en fonction de critères absolus. Mais il ajoute qu'à l'intérieur d'une même culture, rien n'empêche de se référer à d'autres systèmes de valeurs pour réformer et améliorer une société. "Loin de me satisfaire d'un relativisme statique [...], j'en dénonce le péril », affirme-t-il.

Si, en tant qu'ethnologue, Lévi-Strauss se refuse à hiérarchiser les cultures, rien n'empêche à ses yeux de hiérarchiser les valeurs et les modes de vie au sein d'une société donnée. On ne peut, selon lui, taxer de racisme "l'attitude d'individus ou de groupes que leur fidélité à certaines valeurs rend partiellement ou totalement insensibles à d'autres valeurs. Il n'est nullement coupable de placer une manière de vivre et de penser au-dessus de toutes les autres. " (Anthropologie structurale) Bien que toute culture soit le produit d'un lent métissage historique, Lévi-Strauss craint que la vitesse à laquelle ce métissage s'accomplit actuellement ne permette pas aux cultures de procéder à l'intégration harmonieuse des éléments extérieurs. C'est pourquoi il plaide pour le maintien d'une certaine distance entre elles.

Cela vaut aussi pour les cultures occidentales. Bien qu'il s’élève contre l'impérialisme de ces dernières, il en reconnaît la valeur et cherche à les préserver elles aussi devant l'important flux migratoire qu'elles doivent absorber. Dans la perspective lévi-straussienne, l’immigrant, qui concourt au métissage par le bagage culturel qu'il 
apporte, se place en situation d'« assimilation » à la culture dominante qui doit préserver son pouvoir d'intégration. Pour préserver la diversité des cultures, chacune doit donc se défendre sur son territoire national.

Parlant spécifiquement de la France, il souligne « qu'aux XVIIIe et XIXe siècles, son système de valeurs représentait, pour l'Europe et au-delà, un pôle d'attraction. L'assimilation des immigrés ne posait pas de problème. Il n'y en aurait pas davantage aujourd'hui, si, dès l'école primaire et après, notre système de valeurs apparaissait à tous aussi solide, aussi vivant que par le passé. [...] Si les sociétés occidentales ne sont pas capables de conserver ou de susciter des valeurs intellectuelles et morales assez puissantes pour attirer des gens venus du dehors et pour qu'ils souhaitent les adopter, alors il y a lieu de s'alarmer ». (De près et de loin)

Lévi-Strauss défend donc la protection de toutes les cultures, y compris la sienne, qu'il percevait, à la fin de sa vie, tout aussi menacée que les cultures ancestrales. Dans un numéro hors série que lui consacrait le Magazine littéraire en 2003, l'ethnologue livrait cette réflexion : "J'ai commencé à réfléchir à un moment où notre culture agressait d'autres cultures dont je me suis alors fait le défenseur. Maintenant, j'ai l'impression que le mouvement s'est inversé et que notre culture est sur la défensive vis-à-vis des menaces extérieures [...]. Du coup je me sens fermement et ethnologiquement défenseur de ma culture. » Ce ne sont manifestement pas là les propos d'un relativiste social mais ceux d'un homme lucide et franc qui ne se réfugie pas derrière la naïveté d'une rectitude politique qui considère que toutes les pratiques culturelles sont de même valeur.

\section{Religion et laïcité}

Les positions qu'adopte Lévi-Strauss à l'égard des religions sont tout aussi à l'opposé du relativisme multiculturel. Déjà, dans Tristes tropiques (1955), il critique sévèrement l'islam, qu'il perçoit comme rigide et intolérant, et compare la burka à un "appareil orthopédique ». Il se montre par contre plutôt élogieux à l'égard du bouddhisme japonais, qu'il cite comme un exemple de culture réussissant à 
sélectionner puis à assimiler des éléments de l'extérieur sans se mettre en péril.

On ne saurait donc lui reprocher de mettre sur le même pied théocratie et laïcité, féminisme et excision, culture nationale et culture immigrante.

La question peut également être examinée sous l'angle des accommodements religieux. Pour les multiculturalistes, la laïcité va à l'encontre de traditions religieuses qui refusent la séparation de l'État et des religions ; il faut donc, selon eux, limiter la portée de la laïcité afin d'accommoder ces religions. Dans cette logique, la religion fait partie de la culture et l'État doit donc aménager une place à la « culture religieuse » dans ses écoles publiques.

Qu'en pensait Lévi-Strauss ? Il répond sans détour dans une entrevue au Nouvel Observateur le 10 octobre 2002 : "On a le droit de critiquer la religion, dit-il. On a le droit de dire ce qu'on pense. [...] Il en va de même avec l'idée actuelle qu'il faudrait introduire l'enseignement de l'histoire des religions à l'école. [...] Là encore, cela me semble être une concession faite [...] à l'idée que la religion doit pénétrer en dehors de son domaine. Il me semble au contraire que la laïcité pure et dure avait très bien marché jusqu'ici. » Voilà qui cloue le cercueil des supposés fondements lévi-straussiens au relativisme multiculturel.

D’ascendance juive mais athée déclaré, Lévi-Strauss aborde rarement le thème de la religion et chaque fois qu'il le fait, c'est dans un esprit très critique. Il est donc possible, à ses yeux, de défendre le patrimoine culturel national sans qu'il soit pour autant nécessaire de mettre la religion de la majorité au premier plan. Dans le débat qui nous intéresse au Québec, il serait donc à la fois pour la sauvegarde du patrimoine culturel et historique québécois, contre les symboles religieux dans la fonction publique et sûrement contre la présence du crucifix à l'Assemblée nationale. Bref, il serait tout à fait en faveur d'une charte de la laïcité. 
L'auteur est journaliste et anthropologue et auteur, entre autres, de La grande illusion. Comment la sélection naturelle a créé l'idée de Dieu (Multimondes, 2006)

Des commentaires ? Écrivez à Antoine Robitaille. Pour lire ou relire les anciens textes du Devoir de philo ou du Devoir d'histoire: www.ledevoir.com/ societe/le-devoir-de-philo.

Voir l'article du Devoir et les réactions des internautes.

\section{Fin du texte}

